\title{
Antinociceptive Effect of Ghrelin in a Rat Model of Irritable Bowel Syndrome Involves TRPV1/Opioid Systems
}

\author{
Yuqing $\mathrm{Mao}^{\mathrm{a}}$ Zhengyang Li ${ }^{\mathrm{a}} \quad \mathrm{Kan} \mathrm{Chen}^{\mathrm{b}}$ Huafang Yu${ }^{\mathrm{a}}$ Shaoren Zhang ${ }^{\mathrm{a}}$ \\ Miao Jiang ${ }^{a}$ Yuanhua Ma ${ }^{a}$ Chunli Liang ${ }^{a}$ Hongyan Liu ${ }^{a}$ Huanqing Lia \\ Qian Hua ${ }^{a} \mathrm{Hao} \mathrm{Zhou}^{\mathrm{a}}$ Yonghong Sun ${ }^{\mathrm{c}}$ Xiaoming Fan ${ }^{\mathrm{a}}$
}

aDepartment of Gastroenterology and Hepatology, Jinshan Hospital of Fudan University, Shanghai, bDepartment of Gastroenterology and Hepatology, Shanghai Tenth People's Hospital of Tongji University, Shanghai, 'Department of Gastroenterology and Hepatology, Dalian Friendship Hospital, Liaoning, Dalian, China

\section{Key Words}

Ghrelin • IBS • TRPV1 • Opioid receptor • Visceral hypersensitivity

\begin{abstract}
Background/Aims: Irritable bowel syndrome (IBS), defined as recurrent abdominal pain and changes in bowel habits, seriously affects quality of life and ability to work. Ghrelin is a braingut hormone, which has been reported to show antinociceptive effects in peripheral pain. We investigated the effect of ghrelin on visceral hypersensitivity and pain in a rat model of IBS. Methods: Maternal deprivation (MD) was used to provide a stress-induced model of IBS in Wistar rats. Colorectal distension (CRD) was used to detect visceral sensitivity, which was evaluated by abdominal withdrawal reflex (AWR) scores. Rats that were confirmed to have visceral hypersensitivity after MD were injected with ghrelin $(10 \mu \mathrm{g} / \mathrm{kg})$ subcutaneously twice a week from weeks 7 to 8 . [D-Lys3]-GHRP-6 $(100 \mathrm{nmol} / \mathrm{L})$ and naloxone $(100 \mathrm{nmol} / \mathrm{L})$ were administered subcutaneously to block growth hormone secretagogue receptor $1 \alpha$ (GHS-R1 $\alpha)$ and opioid receptors, respectively. Expression of transient receptor potential vanilloid type 1 (TRPV1) and $\mu$ and $k$ opioid receptors (MOR and KOR) in colon, dorsal root ganglion (DRG) and cerebral cortex tissues were detected by western blotting, quantitative real-time polymerase chain reaction (qRT-PCR), immunohistochemical analyses and immunofluorescence. Results: Ghrelin treatment increased expression of opioid receptors and inhibited expression of TRPV1 in colon, dorsal root ganglion (DRG) and cerebral cortex. The antinociceptive effect of ghrelin in the rat model of IBS was partly blocked by both the ghrelin antagonist [D-Lys3]-GHRP-6 and the opioid receptor antagonist naloxone. Conclusion: The results indicate that ghrelin exerted an antinociceptive effect, which was mediated via TRPV1/opioid systems, in IBSinduced visceral hypersensitivity. Ghrelin might potentially be used as a new treatment for IBS.


Mao et al.: Ghrelin Exerts Antinociceptive Effect in a Rat Model of Irritable Bowel Syndrome

\section{Introduction}

Irritable bowel syndrome (IBS), which affects $20 \%$ of people worldwide [1], is a functional bowel disorder that presents with no structural abnormalities and is characterized as chronic, recurrent abdominal pain or discomfort with stool irregularities [2, 3]. IBS has a negative physical and mental impact on quality of life and ability to work, since chronic stomach pain or discomfort limits daily activities and causes mood depression. Although the pathogenesis of IBS remains unclear, visceral hypersensitivity, resulting from increased signal transmission between dorsal horn neurons and the brain, is acknowledged to be a key factor underlying the generation of pain.

The transient receptor potential vanilloid type I (TRPV1 or VR1) receptor, a member of the transient receptor potential superfamily, is a non-selective calcium channel that is activated by capsaicin, protons, membrane-derived lipids and noxious heat [4]. TRPV1, which is expressed mainly by primary afferent neurons sensing noxious stimuli, is acknowledged to play an important role in visceral hypersensitivity and inflammation-induced pain. TRPV1 therefore provides a therapeutic target for the treatment of IBS. Akbar et al. showed that TRPV1-immunoreactive nerve fibers were upregulated in colon tissues from IBS patients and that this upregulation was positively correlated with the severity of abdominal pain [5]. Vardanyan et al. showed that TRPV1 knockout mice do not develop thermal and tactile hyperalgesia [6]. Together, these studies suggest that downregulation of TRPV1 might be an attractive therapeutic strategy for IBS.

The opioid receptor system plays an important role in both central and peripheral transmission of pain and opioid receptors agonists are, therefore, widely used as analgesics. Recently, kappa-opioid agonist showed protective effect against heart failure following myocardial ischemia/reperfusion [7]. Their clinical use of opioid receptor agonist is, however, limited by important side effects, such as tolerance and opioid dependence, as well as by serious opioid withdrawal reactions [8]. A recent study showed that TRPV1 is collocated with the $\mu$ opioid receptor (MOR) and $\kappa$ opioid receptor (KOR) on dorsal root ganglion (DRG) neurons of the spinal cord, indicating crosstalk between the TRPV1 and opioid systems [9]. The opioid agonist morphine exerts its antinociceptive effect partly by inhibition of adenylate cyclase, which inhibits PKA-potentiated TRPV1 responses $[9,10]$. In return, TRPV1 activation contributes to morphine tolerance and opioid-induced hyperalgesia [11].

Ghrelin is a growth hormone produced primarily in the stomach and brain (a brain-gut peptide) that has many physiological functions, including growth promotion, suppression of inflammation and enhancement of food intake [12-15]. There is growing evidence that ghrelin has antinociceptive effects in murine pain models [16-19]. Administration of ghrelin produced a marked dose- and time-dependent attenuation of acute pain in the tail withdrawal and hot-plate tests in mice and GHRP-2, a ghrelin receptor agonist, also produced an antinociceptive effect [18]. Interestingly, there is a delicate interaction between ghrelin and opioid systems. Ghrelin interacts with opioid receptors to regulate the mesolimbic dopaminergic system, which is associated with food reward [20] and the antihyperalgesic effect of ghrelin is reversed by the MOR antagonist, naloxone [17].

Ghrelin is produced mainly by gastrointestinal glands and the hypothalamic arcuate nucleus, which in turn regulates gastrointestinal tract motility and the cranial nervous system. The updated Roman IV diagnostic criteria for functional gastrointestinal disorders, which redefine these as "disorders of gut-brain interaction", fully recognize the interplay between the gastrointestinal tract and the brain. Since ghrelin showed antinociceptive effects in peripheral hyperalgesia, we hypothesized that this brain-gut peptide may also play roles in IBS-induced visceral hyperalgesia. However, little is known about the effect of ghrelin in visceral hyperalgesia or possible mechanisms of action. In the present study, we demonstrated that ghrelin reduced IBS-induced hyperalgesia by upregulating opioid receptors and inhibiting TRPV1. This new understanding provides a rationale for the use of ghrelin as a therapy for IBS-induced hyperalgesia. More importantly, inhibition of TRPV1 by co-administration of ghrelin could reduce morphine doses and thereby attenuate 
Mao et al.: Ghrelin Exerts Antinociceptive Effect in a Rat Model of Irritable Bowel Syndrome

morphine-induced tolerance, dependence and hyperalgesia, which would have major clinical significance.

\section{Materials and Methods}

Animals and experimental protocols

Animals

Eight pregnant Wistar rats were purchased from the Shanghai SLAC Laboratory Animal Co., Ltd. (Shanghai, China). The animals were individually housed in a standard animal facility and maintained on a $12 \mathrm{~h}$ light-dark cycles at constant temperature room $\left(24 \pm 1^{\circ} \mathrm{C}\right)$, with the bedding changed every day. MD was carried out using internationally recognized and validated methodology [21-23]. MD was carried out daily from postnatal day 2 to day 14 for three consecutive hours each day. During this time, the pups were removed from the home cage to a temperature-controlled room $\left(28 \pm 1^{\circ} \mathrm{C}\right)$ and prevented from breast feeding. All control pups remained with their dam. Weaning was performed on day 15 and male pups were selected for further experiments, which were performed at 8 weeks of age.

\section{Experimental protocol}

The colorectal distension (CRD) test was carried out in maternally deprived and control rats to evaluate visceral sensitivity, which was quantified using abdominal withdrawal reflex (AWR) scores. Rats that met the criteria for visceral hypersensitivity were randomly divided into 4 groups, with 8 rats per group: IBS group, rats suffered maternal deprivation and were injected intraperitoneally with saline twice a week for 2 weeks; ghrelin group, rats sufferedmaternal deprivation and were injected intraperitoneally with ghrelin (10 $\mu \mathrm{g} / \mathrm{kg} / \mathrm{d}$, dissolved in saline) twice a week for 2 weeks; ghrelin + [D-Lys3]-GHRP-6 group, rats sufferedmaternal deprivation and were intraperitoneally injected with ghrelin $(10 \mu \mathrm{g} / \mathrm{kg} / \mathrm{d}$, dissolved in saline) and [D-Lys3]-GHRP-6 (100 nmol/L, dissolved in saline) twice a week for 2 weeks; ghrelin + naloxone group, rats were injected intraperitoneally with ghrelin $(10 \mu \mathrm{g} / \mathrm{kg} / \mathrm{d}$, dissolved in saline) and naloxone (100 $\mathrm{nmol} / \mathrm{L}$, dissolved in saline) twice a week for 2 weeks. Rats in negative control (NC) group have not suffered maternal deprivation or drug treatment. At the end of the treatment period, the CRD test was performed again and quantified using AWR scores. The animals were sacrificed at the determined time and brain tissue, distal colon tissue and DRG were collected. All animal experiments were approved by the Animal Care and Use Committee of Shanghai Fudan University.

\section{Patients}

A total of 33 IBS patients ( 14 women and 19 men; aged $50.3 \pm 13.5$ years) and 6 control subjects ( 2 women and 4 men; aged $50.4 \pm 12.6$ years) participated in the study, which was approved by the clinical ethical committee of the Dali Friendship Hospital. All participants gave written informed consent before participation in the study. The diagnosis of IBS was based on the Rome IV criteria. Patients were further subclassified as diarrhea-predominant (IBS-D, 7 women and 10 men; aged $50.1 \pm 10.7$ years) or constipationpredominant (IBS-C, 7 women and 9 men; aged $50.6 \pm 16.4$ years). Controls were selected from patients undergoing colonoscopy for polyps and cancer surveillance, all received negative results. Patients with a history of receiving non-steroidal or other anti-inflammatory drugs or who were taking pain medications were excluded from the study. Patients who suffered from painful disorders were also excluded.

\section{Drugs and chemicals}

Ghrelin was purchased from Prospec (Ness-Ziona, Israel). The ribonucleic acid (RNA) PCR kit was purchased from TaKaRa Biotechnology (Dalian, China). Naloxone hydrochloride and [D-Lys3]-GHRP-6 were obtained from Tocris Bioscience (Minneapolis, MN, USA). Anti-MOR and anti-KOR antibodies were purchased from Biosynthesis Biotechnology Co., Ltd. (Beijing, China) and anti-ghrelin antibody was purchased from R\&D Systems (Minneapolis, MN, USA). Anti-IL-1 $\beta$ and anti-IL-6 antibodies were obtained from Cell Signaling Technology (Danvers, MA, USA) and anti-TRPV1 antibody was obtained from Abcam (Cambridge, MA, USA). 


\section{CRD test for antinociceptive activity}

The rats were lightly anesthetized by inhalation of halothane for $1 \mathrm{~min}$ in a sealed cage connected to an animal anesthesia machine. A flexible balloon guide wire (a gift from the Vascular Intervention Department of Shanghai Tenth People's Hospital) was then quickly inserted intra-anally approximately $1.5 \mathrm{~cm}$ into the descending colon and firmly secured by adhesive tape. The animals were placed in a restraint chamber that prevented them from escaping or turning around and allowed to fully recover from the anesthesia for $3 \mathrm{~min}$. The rats were acclimatized to the new environment for $10 \mathrm{~min}$ before the CRD test to minimize interference from stress reactions. When the rats had calmed down and were accustomed to the new conditions, the balloon was slowly inflated from 0 to $80 \mathrm{mmHg}$, using the balloon vasodilation catheter to control the inflation. The balloon was deflated at the end of each $10 \mathrm{~min}$ period and a $10 \mathrm{~min}$ recovery period was allowed between each distention. The responses of the rats were carefully observed until pain behaviors appeared. The AWR was scored as follows: 0 , no pain behaviors; 1, brief head movement followed by immobility; 2, contraction of abdominal muscles; 3 , lifting of abdomen and 4, body arching and lifting of pelvic structures. Each test was observed by two blinded observers and performed in triplicate.

Real-time quantitative reverse transcriptase polymerase chain reaction (qRT-PCR)

Total RNA was extracted from fixed tissues with TRIzol reagent (Tiangen Biotech, Beijing, China). SYBR Green qRT-PCR was performed using the 7900HT Fast Real-Time PCR system (Applied Biosystems, Foster City, CA, USA) to determine expression of mRNA. The primers used are listed in Table 1.

\section{Western blotting}

Total proteins were prepared and quantified using routine procedures. Proteins were separated and transferred to polyvinylidene fluoride membranes. The membranes were incubated overnight at $4^{\circ} \mathrm{C}$ with primary antibodies and incubated with secondary antibodies for $1 \mathrm{~h}$ on the following day. Proteins were detected using an Odyssey two-color infrared laser imaging system (LI-COR Biosciences, Lincoln, NE, USA).

\section{Biochemical assays}

Pro-inflammatory cytokines TNF- $\alpha$ and IL-6 in serum were measured using ELISA kits (R\&D Systems, Minneapolis, MN, USA), according to the manufacturer's instructions.

\section{Immunofluorescence staining}

Tissues sections $(4 \mu \mathrm{m})$ were fixed with $4 \%$ paraformaldehyde for $30 \mathrm{~min}$ and washed three times with phosphate buffer saline (PBS). Sections were separately incubated overnight with primary antibodies against KOR, MOR and TRPV1 $(1: 100)$ at $4{ }^{\circ} \mathrm{C}$, followed by incubation with secondary antibody for $30 \mathrm{~min}$. All images were acquired using ZEN software (Carl Zeiss AG, Jena, Germany).

\section{Histopathological analysis}

Colon tissues from the rats were fixed in $4 \%$ paraformaldehyde for at least $24 \mathrm{~h}$ and then embedded in paraffin. Sections $(5 \mu \mathrm{m})$ were prepared, stained with hematoxylin and eosin (HE) and observed by light microscopy.

\section{Immunohistochemical analysis}

Tissue sections $(4 \mu \mathrm{m})$ were dried overnight, dewaxed and rehydrated. Sections were then blocked with $10 \%$ goat serum for $30 \mathrm{~min}$ and incubated with primary antibodies against KOR, MOR, TRPV1, IL-1 $\beta$ and IL-6 (1:500) overnight at $4{ }^{\circ} \mathrm{C}$, followed by incubation with secondary antibody for 60 min. Each section was observed using a light microscope and the images were recorded. Three different fields of each section were randomly chosen and the ratio of positive area to total area was determined using
Table 1. Nucleotide sequences of primers used for PCR

\begin{tabular}{|c|c|c|}
\hline Gene & & Primer sequence $\left.5^{\prime}-3^{\prime}\right)$ \\
\hline \multirow{2}{*}{ KOR } & Forward & GCAGCCTGAATCCTGTTCTC \\
\hline & Reverse & ТСАТСССТСССАСАТСТСТС \\
\hline \multirow{2}{*}{ MOR } & Forward & CAACTTGTCCCACGTTGATG \\
\hline & Reverse & TCCAAAGAGGCCCACTACAC \\
\hline \multirow{2}{*}{ IL-6 } & Forward & GAAAACACCAGGGTCAGCAT \\
\hline & Reverse & CAGCCACTGGTTTTTCTGCT \\
\hline \multirow{2}{*}{ TNF- $\alpha$} & Forward & СТССТАСССGAACAAGGTCA \\
\hline & Reverse & CGGTCACССTTCTCCAACT \\
\hline \multirow{2}{*}{ GAPDH } & Forward & GGTGAAGGTCGGTGTGAACG \\
\hline & Reverse & GTGAAGACACCAGTAGACTC \\
\hline
\end{tabular}


Mao et al.: Ghrelin Exerts Antinociceptive Effect in a Rat Model of Irritable Bowel Syndrome

Image-Pro Plus 6.0 imaging software (Media Cybernetics, Inc., Rockville, MD, USA). The average of the three ratios was used for statistical analysis.

\section{Statistical analysis}

Data are shown as means \pm SD. The Student's t test was used for comparisons between two groups and Tukey's post hoc test was used for comparisons among multiple groups. All statistical analyses were performed using GraphPad Prism version 6.0 software for Windows (San Diego, CA, USA). $P$ value $<0.05$ was considered to be statistically significant.

\section{Results}

Maternal deprivation during neonatal period caused visceral hypersensitivity to colorectal distention in rats

Higher scores in the CRD test were observed in the MD group than in the NC group at pressures of 30, 45 and $60 \mathrm{~mm} \mathrm{Hg}$, but not at $15 \mathrm{~mm} \mathrm{Hg}$. The MD group also had a decreased threshold pressure compared with the NC group (Fig. 1A). Western blotting, qRT-PCR and immunohistochemical analyses showed that expression of TRPV1 was significantly increased in colon tissue, cerebral cortex and DRG of rats in the IBS group, compared with animals in the NC group (Fig. 2 and 4). Immunofluorescence images from the MD group also showed brighter spots than images from the NC group (Fig. 3-5), indicating that expression of TRPV1 in the MD group was significantly increased compared with the NC group. HE staining showed no obvious differences in histopathological structures between the model group and the NC group (Fig. 6D). All of these results indicate that MD successfully increased visceral hypersensitivity in the present study.

Fig. 1. Visceral sensitivity and pain thresholds were detected by CRD and AWR scores. (A) MD group had higher AWR scores than NC group with CRD pressures of 30,45 and $60 \mathrm{~mm} \mathrm{Hg}$, but not $15 \mathrm{~mm}$ Hg. MD group also had decreased threshold pressure compared with NC group. (B) MD + ghrelin group had higher AWR scores than MD group with CRD pressures of 30 , 45 and $60 \mathrm{~mm} \mathrm{Hg}$, but not $15 \mathrm{~mm} \mathrm{Hg}$. MD + ghrelin group also had increased threshold pressure compared with MD group. (C) [D-lys3]-GHRP-6 group had increased AWR scores with the same CRD pressure and reduced threshold pressure compared with MD + ghrelin group. (D) Naloxone group had significantly increased AWR scores with the same CRD pressure and reduced threshold pressure compared with MD + ghrelin group. ( $\mathrm{P}<0.05$ for MD group versus NC group; $" \mathrm{P}<0.05$ for $\mathrm{MD}+$ ghrelin group versus $\mathrm{MD}$ group; ${ }^{\mathrm{S}}<0.05$ for ghrelin $+\left[\right.$ D-lys $\left.{ }^{3}\right]$-GHRP-6 group versus MD + ghrelin group; ${ }^{\circledR} \mathrm{P}<0.05$ for ghrelin + naloxone group versus MD + ghrelin group).

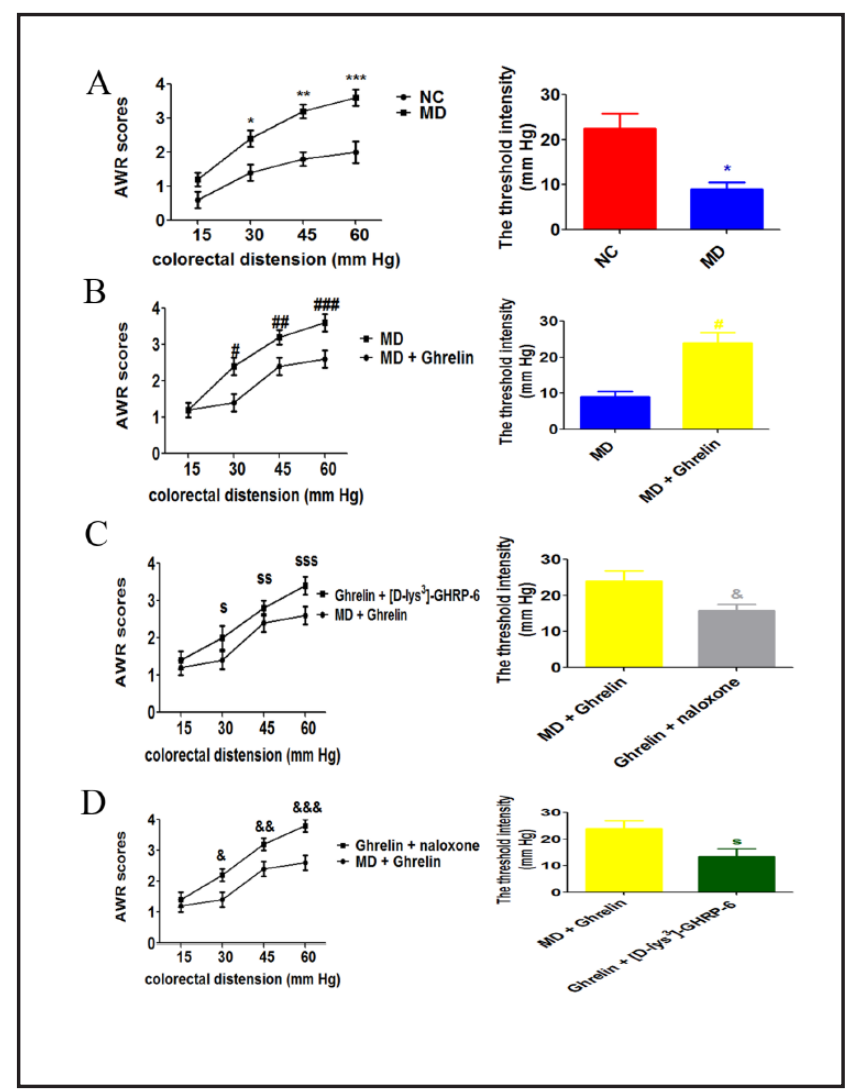


Fig. 2. Ghrelin treatment attenuated visceral hypersensitivity in response to CRD and effect was reversed by [D-lys3]-GHRP-6 and naloxone. (A) Levels of TRPV1, KOR and MOR protein in colon tissues, detected by western blotting. (B) Levels of TRPV1, KOR and MOR mRNA in colon tissues, detected by qRT-PCR. (C) Immunohistochemistry staining $(200 x)$ showed expression of TRPV1, KOR and MOR in colon tissues of each group. $\quad\left({ }^{*} \mathrm{P}<0.05\right.$ for MD group versus NC group, $\quad \mathrm{P}<0.05$ for $\mathrm{MD}$ + ghrelin group versus MD group, ${ }^{\mathrm{s}} \mathrm{P}<0.05$ for ghrelin + [D-lys3]-GHRP-6 group versus $\mathrm{MD}+$ ghrelin group, ${ }^{\&} \mathrm{P}<0.05$ for ghrelin + naloxone group versus $\mathrm{MD}+$ ghrelin group).

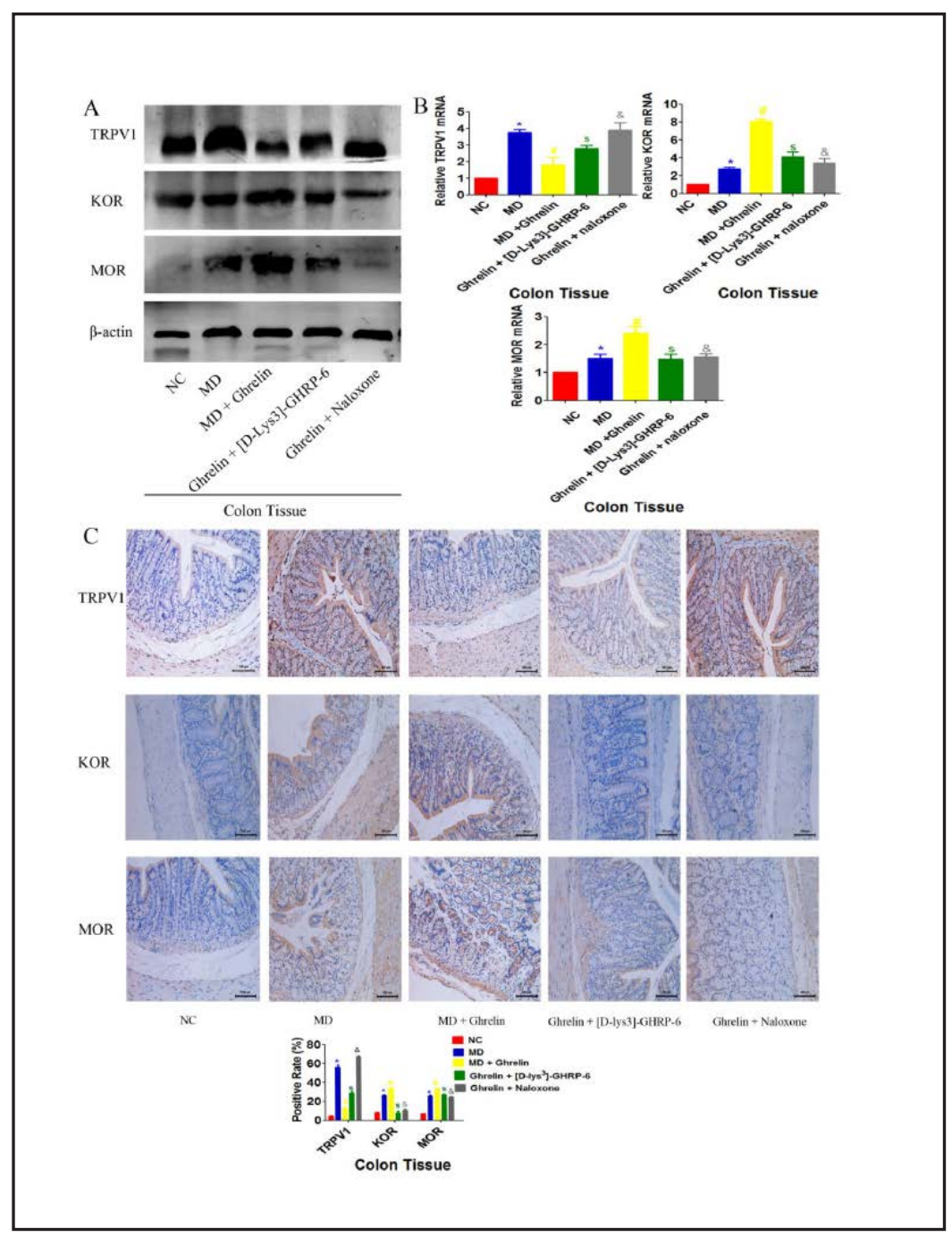

Ghrelin treatment attenuated visceral hypersensitivity and visceralgia in response to CRD in rat model of IBS

Ghrelin treatment significantly lowered AWR scores at CRD pressures of 30, 45 and 60 $\mathrm{mm} \mathrm{Hg}$, but not at $15 \mathrm{~mm} \mathrm{Hg}$ (Fig. 1B), and also increased the threshold pressure compared with the MD group. Western blotting, qRT-PCR and immunohistochemical analyses showed that expression of TRPV1 was markedly reduced in colon tissue, cerebral cortex and DRG of rats in the ghrelin-treated group, compared with the MD group (Fig. 2, 4 and 6). Dimmer immunofluorescence staining was observed in the ghrelin-treated group compared with the MD group (Fig. 3-5), indicating that ghrelin treatment reduced TRPV1 expression compared with MD group. Ghrelin treatment thus attenuated MD-induced visceral hypersensitivity and increased the threshold of pain caused by CRD.

Antinociceptive effect of ghrelin may be mediated partly through the ghrelin receptor

In the CRD test, rats in the ghrelin + [D-Lys3]-GHRP-6 group showed a lower threshold for visceral pain compared with the MD + ghrelin group (Fig. 1C). Rats in the [D-Lys3]-GHRP-6 group also exhibited more frequent and stronger abdominal contractions than rats in the MD + ghrelin group, in response to the same colorectal pressure. Additionally, expression of TRPV1 in cerebral cortex, colon tissue and DRG was increased in the [D-Lys3]-GHRP-6 group compared with the ghrelin-treated group (Fig. 2-6). We suggest, therefore, that the antinociceptive effect of ghrelin may be mediated partly through the ghrelin receptor. 
Mao et al.: Ghrelin Exerts Antinociceptive Effect in a Rat Model of Irritable Bowel Syndrome

Fig. 3. Expression of TRPV1 in colon tissues assessed by immunofluorescence. (A) Ghrelin significantly reduced MD-induced increase of TRPV1, as indicated by intensity of green fluorescence in colon tissues. $\left({ }^{*} \mathrm{P}<0.05\right.$ for MD group versus NC group, ${ }^{*} \mathrm{P}<0.05$ for $\mathrm{MD}$ + ghrelin group versus MD group, ${ }^{\mathrm{s}} \mathrm{P}<0.05$ for ghrelin + [D-lys3]GHRP-6 group versus $\mathrm{MD}+$ ghrelin group, ${ }^{\&} \mathrm{P}<0.05$ for ghrelin + naloxone group versus $\mathrm{MD}+$ ghrelin group).

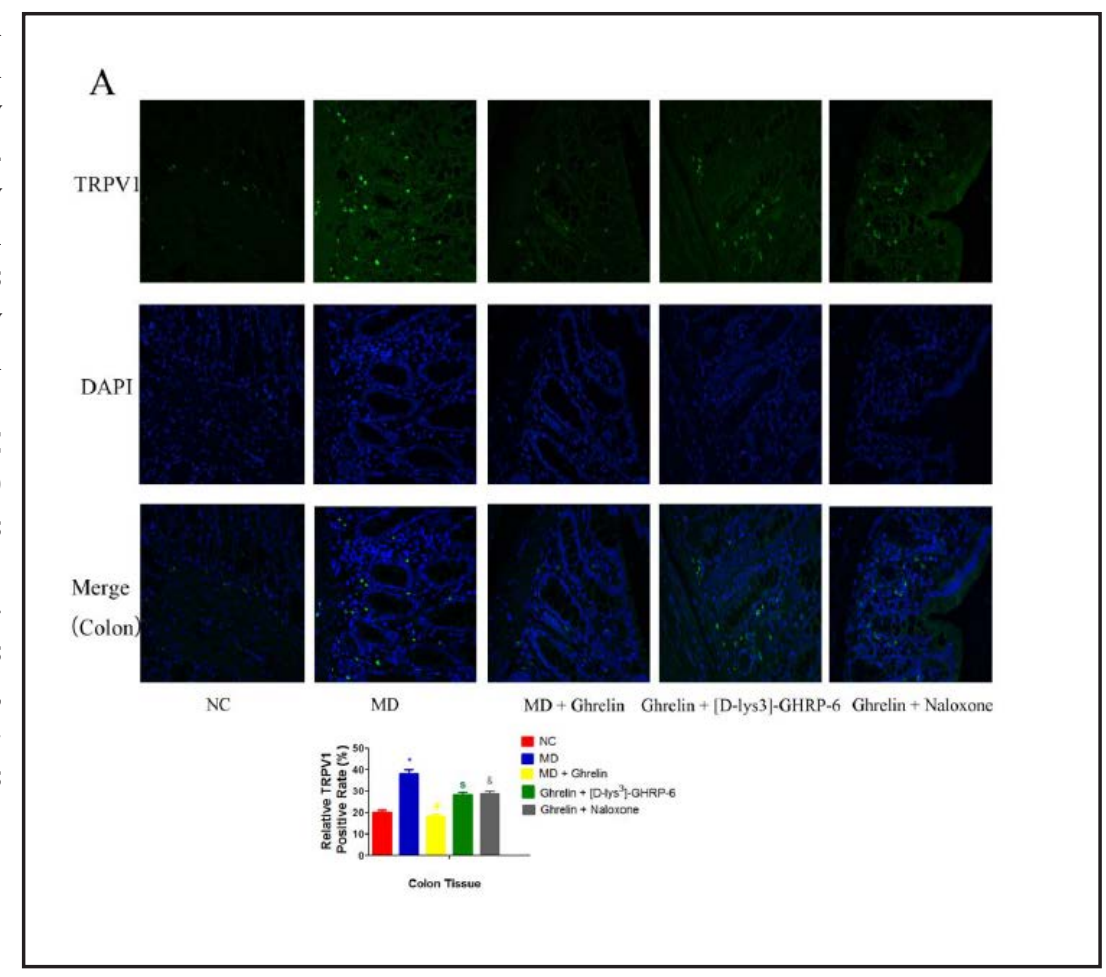

Fig. 4. (A) Detection of TRPV1, KOR and MOR mRNA levels in DRG tissues detected by qRTPCR. (B) Co-expression of TRPV1 and KOR in DRG tissues, assessed by immunofluorescence. Green fluorescence indicates KOR and red fluorescence indicates TRPV1. White arrows indicate areas co-expressing TRPV1 and KOR. $\left({ }^{*} \mathrm{P}<0.05\right.$ for MD group versus $\mathrm{NC}$ group, ${ }^{\#} \mathrm{P}<0.05$ for $\mathrm{MD}+$ ghrelin group versus $\mathrm{MD}$ group, ${ }^{\mathrm{s}} \mathrm{P}<0.05$ for ghrelin + [D-lys3]-GHRP-6 group versus MD + ghrelin group, ${ }^{\&} \mathrm{P}<0.05$ for ghrelin + naloxone group versus MD + ghrelin group).

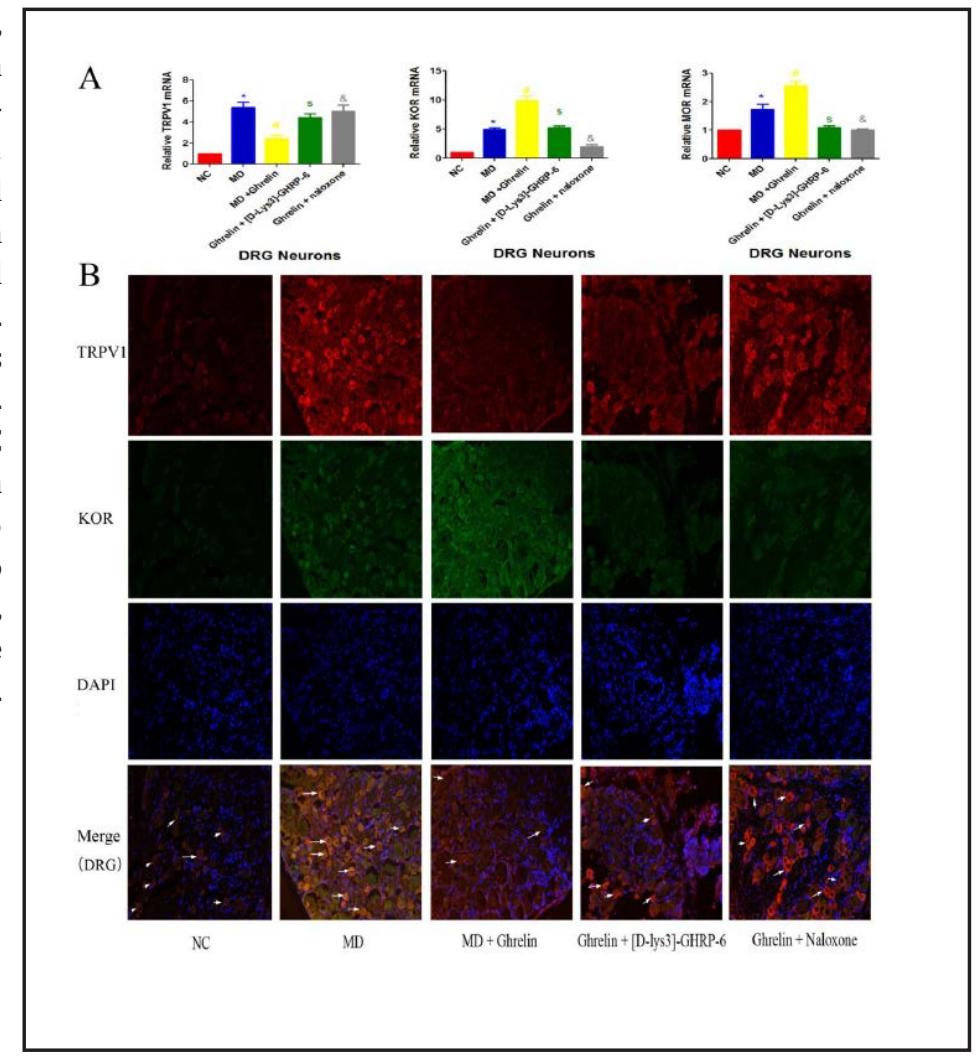

Antinociceptive effect of ghrelin may be partly mediated through opioid receptors

Rats in the ghrelin + naloxone group showed a lower threshold for visceral pain than rats in the ghrelin group (Fig. 1D). Moreover, ghrelin treatment significantly increased the 
Fig. 5. (A) Co-expression of TRPV1 and MOR in DRG tissues assessed by immunofluorescence. Green fluorescence indicates MOR and red fluorescence indicates TRPV1. White arrows indicate areas coexpressing TRPV1 and MOR.

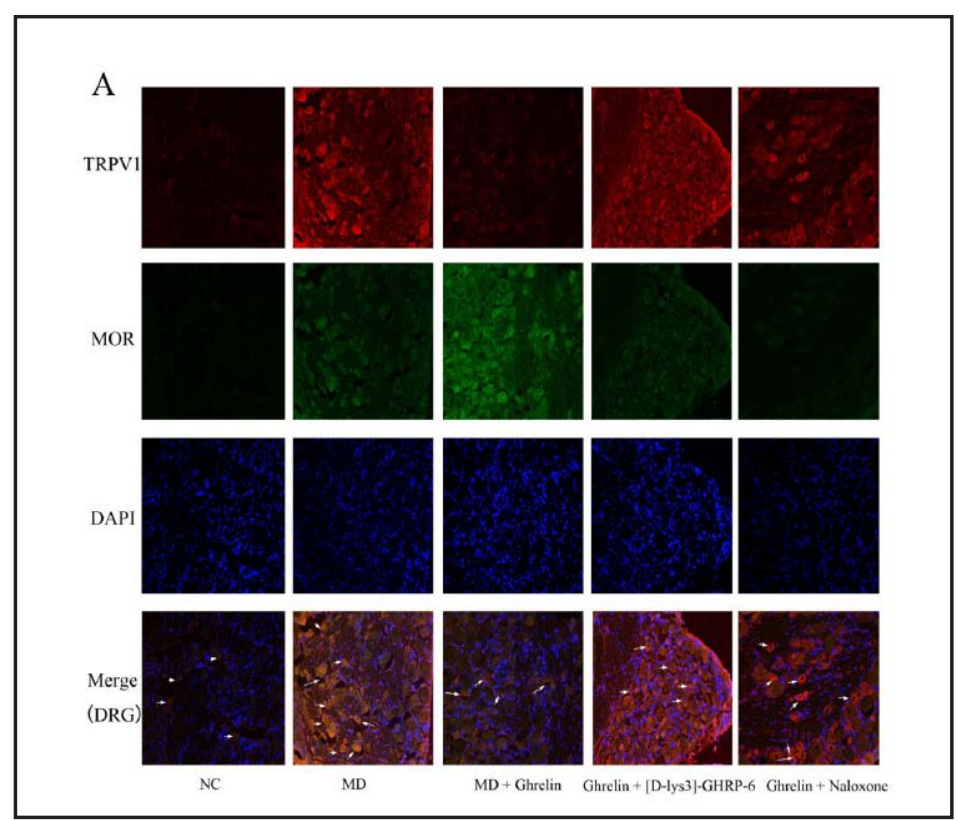

Fig. 6. Ghrelin treatment reduced expression of TRPV1 and increased expression of opioid receptors in cerebral cortex and effect was reversed by [D-lys3]GHRP-6 and naloxone. (A) Detection of TRPV1, KOR and MOR proteins in brain tissues by western blotting. (B) Expression of TRPV1, KOR and MOR mRNA in brain tissues detected by qRTPCR. (C) Immunohistochemical staining (200×), showing expression of TRPV1, KOR and MOR in cerebral cortex tissues. (D) Observation of histological structure of colon tissues by HE staining. $\left({ }^{*} \mathrm{P}<0.05\right.$ for MD group versus NC group, ${ }^{*} \mathrm{P}<0.05$ for $\mathrm{MD}+$ ghrelin group versus $\mathrm{MD}$ group, ${ }^{\mathrm{S}} \mathrm{P}<0.05$ for ghrelin + [D-lys3]-GHRP-6 group versus $\mathrm{MD}+$ ghrelin group ${ }^{\&} \mathrm{P}<0.05$ for ghrelin + naloxone group versus MD + ghrelin group)
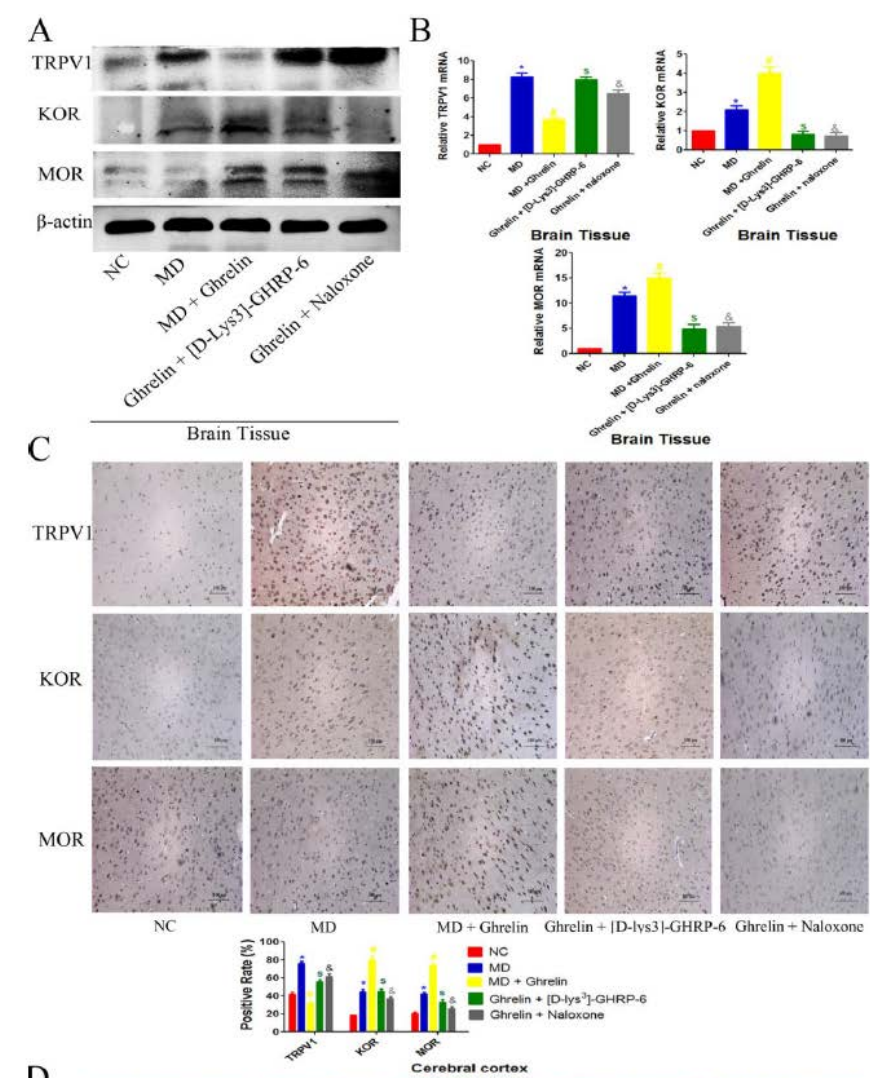

D

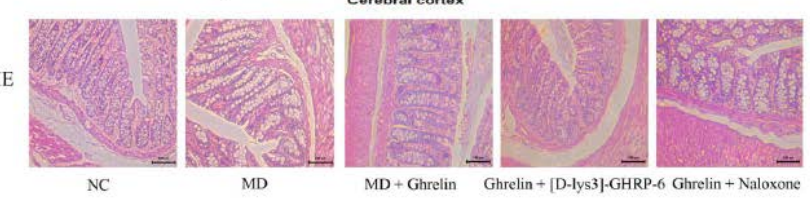


Mao et al.: Ghrelin Exerts Antinociceptive Effect in a Rat Model of Irritable Bowel Syndrome

expression of KOR and MOR in cerebral cortex, , colontissue and DRG (Fig. 2-6). Interestingly, expression of both KOR and MOR was reduced by naloxone treatment and was accompanied by a marked increase of TRPV1 expression in the ghrelin + naloxone group (Fig. 2-6). Therefore, we suggest that the antinociceptive effect of ghrelin might be mediated partly by opioid receptors.

Ghrelin treatment reduced release of inflammatory cytokines in rats in the MD group

Western blotting and qRT-PCR results showed that ghrelin treatment reduced the expression of IL- 6 and TNF- $\alpha$ in colon tissues of the MD group (Fig. 7A and B). Serum levels of IL- 6 and TNF- $\alpha$ were also higher in rats in the MD group than in rats in the NC group. Levels were attenuated by ghrelin treatment but the attenuation was reversed by co-administration of [D-Lys3]-GHRP-6 (Fig. 7C). Immunohistochemical analysis also showed that expression of IL- 6 and TNF- $\alpha$ was increased in the MD group and reduced by ghrelin treatment (Fig. 7D). From these results, we conclude that MD induced chronic colonic inflammation, which could be attenuated by ghrelin treatment, partly via growth hormone secretagogue receptor $1 \alpha$ (GHS-R1 $\alpha$ ).

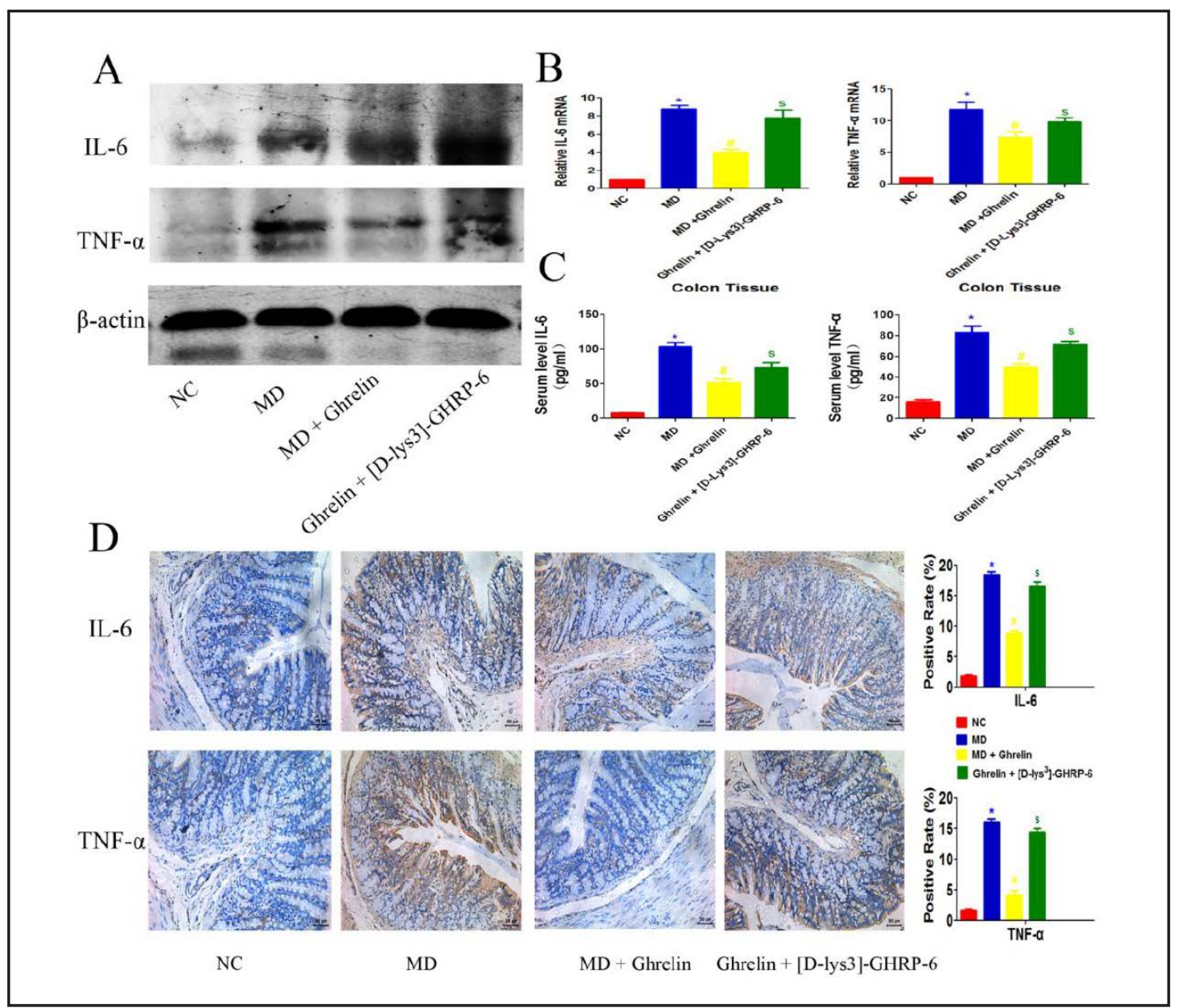

Fig. 7. Ghrelin treatment reduced expression of inflammatory cytokines in colon tissues and effect was reversed by [D-lys3]-GHRP-6. (A) Detection of IL-6 and TNF- $\alpha$ proteins in colon tissues by western blotting. (B) Expression of IL- 6 and TNF- $\alpha$ mRNA in brain tissues detected by qRT-PCR. (C) Serum levels of IL- 6 and TNF- $\alpha$ detected by ELISA. (D) Immunohistochemical staining (200x) showing expression of IL- 6 and TNF- $\alpha$ in colon tissues. $\left({ }^{*} \mathrm{P}<0.05\right.$ for MD group versus $\mathrm{NC}$ group, ${ }^{*} \mathrm{P}<0.05$ for $\mathrm{MD}+$ ghrelin group versus $\mathrm{MD}$ group, ${ }^{\mathrm{s}} \mathrm{P}<0.05$ for ghrelin + [D-lys3]-GHRP-6 group versus MD + ghrelin group). 


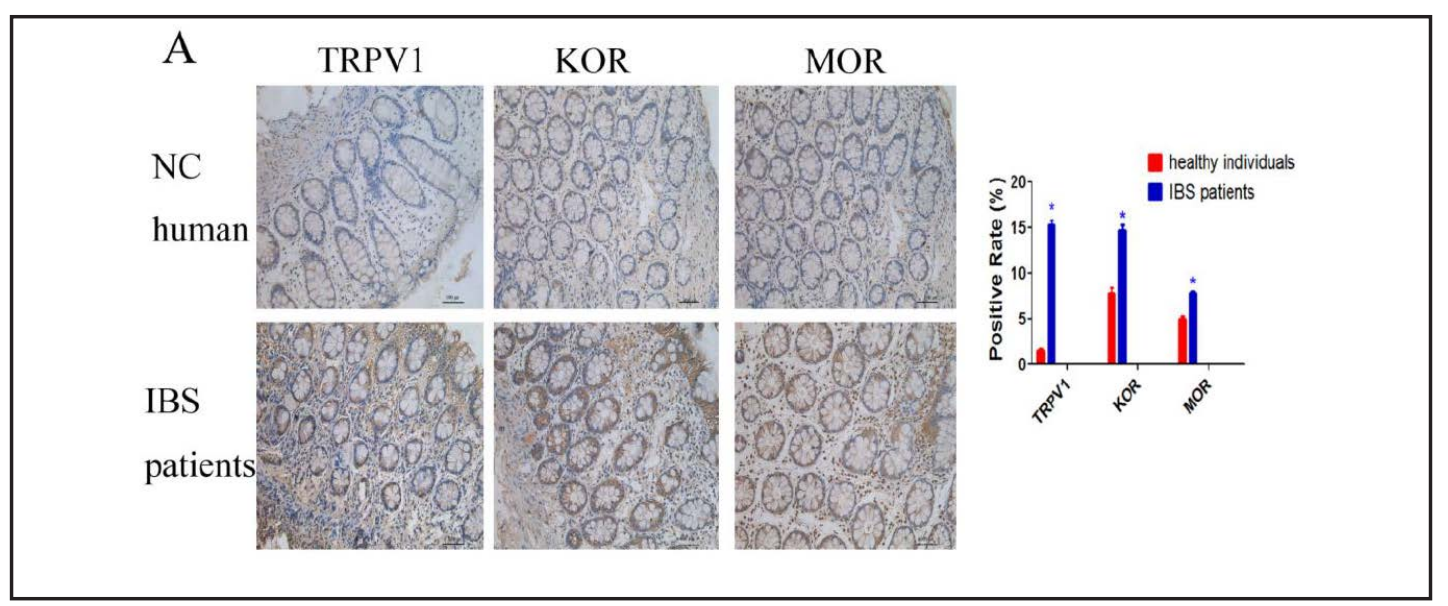

Fig. 8. Expression of TRPV1 and opioid receptors in patients with IBS and healthy individuals. (A) Immunohistochemical staining (200x) showing expression of TRPV1 and opioid receptors in colon tissues of patients with IBS and healthy individuals $(* \mathrm{P}<0.05$ for patients with IBS versus healthy individuals).

Expression of TRPV1 and opioid receptors in patients with irritable bowel syndromeand healthy individuals

Immunohistochemical analyses showed that expression of TRPV1 was significantly increased in colon tissues from patients with IBS compared with tissues from healthy individuals (Fig. 8A). Similarly, the expressions of KOR and MOR were also significantly increased in IBS patients compared with healthy individuals (Fig. 8A). These results indicate that the increased expressions of opioid receptors may be a protective response to inhibit TRPV1 and reduced the visceral pain.

\section{Discussion}

This study provides new evidence that ghrelin plays a critical role in reducing MDinduced visceral hyperalgesia and attenuates visceral pain caused by CRD. We firstly demonstrated that the antinociceptive effect of ghrelin involves TRPV1/opioid systems in a rat model of IBS.

IBS is characterized by the Roman IV diagnostic criteria as a type of brain-gut disorder. The integrated bidirectional connection between the central nervous system and the enteric nervous system is defined as the brain-gut axis. The brain-gut axis is known to be composed of receptors, afferent fibers and efferent fibers, which are major components of the autonomic nervous system [24]. Ghrelin is a brain-gut hormone, which exerts antinociceptive effects in peripheral pain. Little is known about ghrelin and IBS but we now speculate that ghrelin might attenuate visceral hypersensitivity or pain in a rat model of IBS. Furthermore, ghrelin receptor agonist has been demonstrated to trigger defecation in rodents with constipation due to a low-fiber diet and patients with gastroparesis $[25,26]$. Therefore, ghrelin might be a therapeutic medicine for IBS.

TRPV1 is a nonselective ion channel, expressed mainly on nociceptive sensory neurons, which is essential for visceral hypersensitivity to inflammation and mechanical stimulation $[27,28]$. Recognized as a visceral mechanoreceptor, TRPV1 has an important role in inducing hypersensitivity to mechanical stimulation [29]. The opioid system is closely associated with pain threshold and the brain-gut axis. Opioid receptors such as KOR and MOR are widely expressed in the thalamus, the medial brain ventricle, DRG and colon tissues. Schroeder reported that high voltage-activated calcium currents can be reduced by opioid receptor-activated inhibitory G-proteins $\left(\mathrm{G}_{\mathrm{i}}\right)$ in cultured DRG neurons [30]. Opioid receptors are reported to modulate TRPV1 activation [31]. Binding of opioids to their receptors

\section{KARGER}




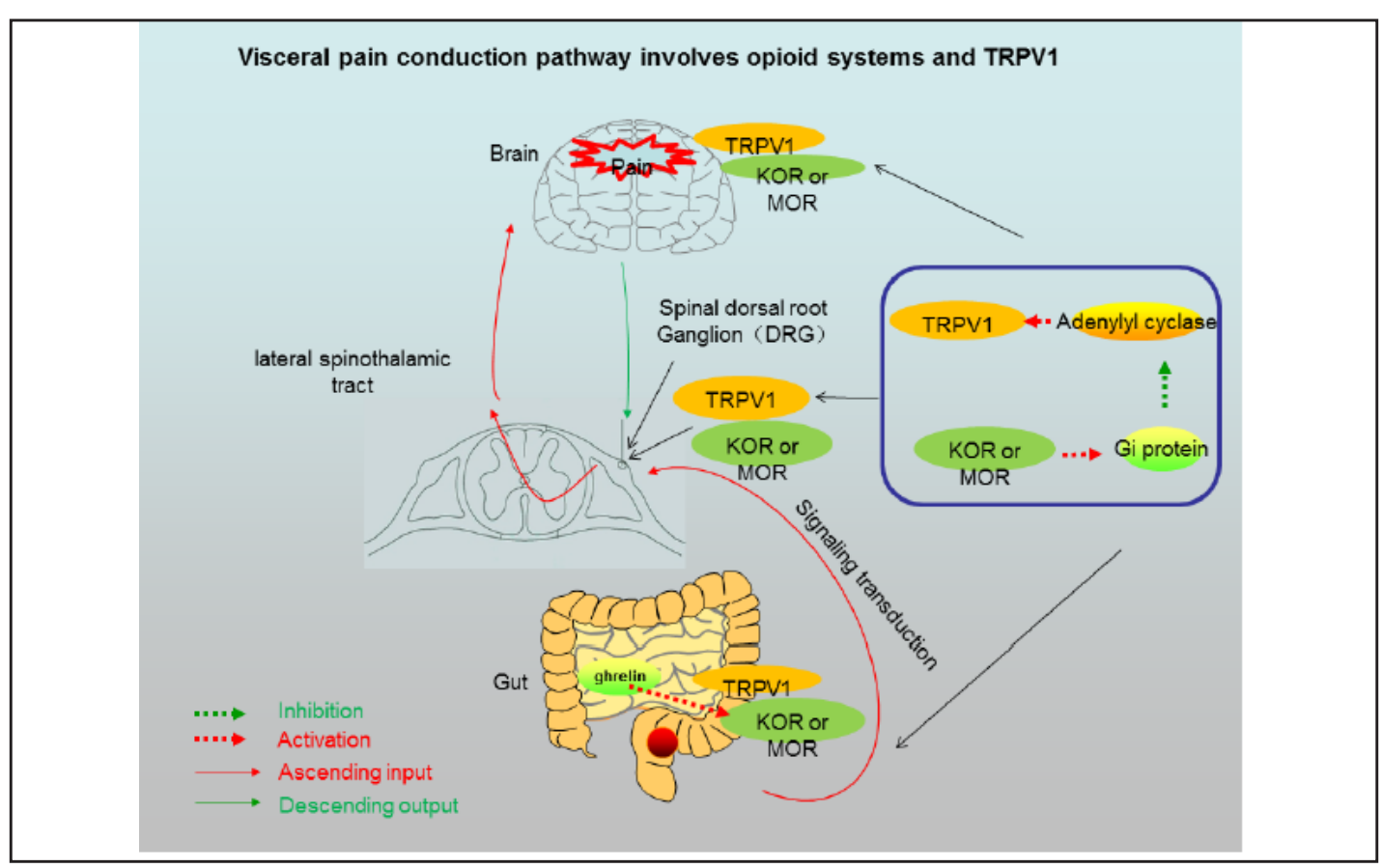

Fig. 9. Visceral pain conduction pathway involves opioid systems and TRPV1. The chronic stress of MD increased expression of TRPV1 in neurons of colon tissues and initiated a signal transmitted via the parasympathetic nervous system that terminated in the spinal DRG. The signal then crossed into the spinal section and ascending input was transmitted via the lateral spinothalamic tract to finally arrive in the brain. Activating opioid receptors, such as KOR and MOR, in the colon DRG and brain will reduce adenylyl cyclase activity, primarily through $G_{i}$ proteins and inhibit the activation of TRPV1. Ghrelin treatment will activate opioid receptors, which suppress TRPV1. This effect is present in the colon, DRG and brain. The weak signal is transmitted via the DRG and the lateral spinothalamic tract to subcortical and cortical structures. The sensation of pain is thus attenuated and the pain threshold is increased.

leads to dissociation of the heterotrimeric $G$ protein complex into $G_{\alpha}$ and $G_{\beta \gamma}$ subunits, which inhibit adenylyl cyclase activity and reduce cyclic adenosine monophosphate (cAMP) levels and protein kinase A (PKA) activation. TRPV1 could be suppressed with the help of cAMP and PKA $[32,33]$. We showed that the expression of TRPV1 and opioid receptors is increased in colon tissues from IBS patients compared with those from healthy individuals. We suggest that the increased expression of opioid receptors is a compensatory response to inhibit TRPV1 and attenuate the visceral pain.

We showed that TRPV1, KOR and MOR are co-expressed in the DRG, cerebral cortex and colon tissue in a rat model of IBS. As expected, ghrelin showed marked antinociceptive effects in MD-induced visceral hyperalgesia. Furthermore, protein and mRNA levels of the opioid receptors KOR and MOR were significantly increased in the ghrelin-treated group compared with the MD group, accompanied by marked reduction of TRPV1 expression. We used naloxone, a nonselective opioid receptor antagonist, to determine whether the antinociceptive effect of ghrelin was dependent on opioid receptors. Rats treated with both ghrelin and naloxone showed higher AWR scores in response to the same colonic pressure. Interestingly, the increase of TRPV1 was accompanied by opioid receptor blockade. Our results suggest that the antinociceptive effect of ghrelin is mediated, at least in part, via opioid receptors. Although the antinociceptive effect of ghrelin was attenuated by [D-Lys3]-GHRP-6, a selective antagonist of GHS-R $\alpha$, we were unable to conclude that GHS-R is necessary for ghrelin to exert its analgesic effect. Whether ghrelin binds directly to opioid receptors or to other unknown receptors remains a subject for further studies.

\section{KARGER}


Karolina et al. have reported that ghrelin interacts with neuropeptide Y receptor Y1 and opioid receptors to increase food reward [34]. Our research provides further evidence that ghrelin connects the brain and the gut. Ghrelin has also been shown to upregulate opioid receptors and subsequently inhibit TPRV1 activation via the cAMP/PKA pathway [10]. The chronic stress of MD increased expression of TRPV1 in neurons in colon tissues and initiated a signal that was transmitted via the parasympathetic nervous system and terminated in the spinal DRG. The signal then crossed into the spinal section and ascending input was transmitted via the lateral spinothalamic tract to finally arrive in the brain. Ghrelin treatment will activate opioid receptors such as KOR and MOR and thereby reduce adenylyl cyclase activity, primarily through $\mathrm{G}_{i}$ proteins, and inhibit activation of TRPV1. This effect is present in the colon, DRG and brain. The weak signal is transmitted via the DRG, through the lateral spinothalamic tract, to subcortical and cortical structures. The feeling of pain is thus attenuated and the pain threshold is increased (Fig. 9).

In conclusion, we have shown that ghrelin reduces visceral hypersensitivity via regulation of TRPV1 and opioid receptors, suggesting that ghrelin might be a promising new therapy for IBS.

\section{Acknowledgements}

This work was supported by a Research Grant for Key Clinical Discipline Construction of Jinshan District, Shanghai Municipality, China, No. JSZK2015A06.

\section{Disclosure Statement}

The authors declare no conflicts of interests.

\section{References}

1 Lovell RM, Ford AC: Global prevalence of and risk factors for irritable bowel syndrome: a meta-analysis. Clin Gastroenterol Hepatol 2012;10:712-721.

-2 Yu YB, Zuo XL, Zhao QJ, Chen FX, Yang J, Dong YY, Wang P, Li YQ: Brain-derived neurotrophic factor contributes to abdominal pain in irritable bowel syndrome. Gut 2012;61:685-694.

$>3$ Longstreth GF, Thompson WG, Chey WD, Houghton LA, Mearin F, Spiller RC: Functional bowel disorders. Gastroenterology 2006;130:1480-1491.

4 Tominaga M, Caterina MJ, Malmberg AB, Rosen TA, Gilbert H, Skinner K, Raumann BE, Basbaum AI, Julius D: The cloned capsaicin receptor integrates multiple pain-producing stimuli. Neuron 1998;21:531-543.

5 Akbar A, Yiangou Y, Facer P, Brydon WG, Walters JR, Anand P, Ghosh S: Expression of the trpv1 receptor differs in quiescent inflammatory bowel disease with or without abdominal pain. Gut 2010;59:767-774.

-6 Vardanyan A, Wang R, Vanderah TW, Ossipov MH, Lai J, Porreca F, King T: Trpv1 receptor in expression of opioid-induced hyperalgesia. J Pain 2009;10:243-252.

7 Tong G, Zhang B, Zhou X, Zhao J, Sun Z, Tao Y, Pei J, Zhang W: Kappa-opioid agonist u50, 488h-mediated protection against heart failure following myocardial ischemia/reperfusion: dual roles of heme oxygenase-1. Cell Physiol Biochem 2016;39:2158-2172.

-8 Spahn V, Fischer O, Endres-Becker J, Schafer M, Stein C, Zollner C: Opioid withdrawal increases transient receptor potential vanilloid 1 activity in a protein kinase a-dependent manner. Pain 2013;154:598-608.

- Endres-Becker J, Heppenstall PA, Mousa SA, Labuz D, Oksche A, Schafer M, Stein C, Zollner C: Mu-opioid receptor activation modulates transient receptor potential vanilloid 1 (trpv1) currents in sensory neurons in a model of inflammatory pain. Mol Pharmacol 2007;71:12-18.

10 Vetter I, Wyse BD, Monteith GR, Roberts-Thomson SJ, Cabot PJ: The mu opioid agonist morphine modulates potentiation of capsaicin-evoked trpv1 responses through a cyclic amp-dependent protein kinase a pathway. Mol Pain 2006;2:22.

11 Chen Y, Geis C, Sommer C: Activation of trpv1 contributes to morphine tolerance: involvement of the mitogen-activated protein kinase signaling pathway. J Neurosci 2008;28:5836-5845.

12 Yang D, Liu Z, Yang Z: Ghrelin and its relation with n-terminal brain natriuretic peptide, endothelin-1 and nitric oxide in patients with idiopathic pulmonary hypertension. Cardiology 2013;124:241-245. 


\section{Cellular Physiology Cell Physiol Biochem 2017;43:518-530 \begin{tabular}{l|l|l|l|}
\hline DOI: 10.1159/000480478 2017 The Author(s). Published by S. Karger AG, Basel & $\begin{array}{l}\text { C) } \\
\text { www.karger.com/cpb }\end{array}$
\end{tabular}

Mao et al.: Ghrelin Exerts Antinociceptive Effect in a Rat Model of Irritable Bowel Syndrome

13 Zeng M, He W, Li L, Li B, Luo L, Huang X, Guan K, Chen W: Ghrelin attenuates sepsis-associated acute lung injury oxidative stress in rats. Inflammation 2015;38:683-690.

14 Aoki H, Nakata M, Dezaki K, Lu M, Gantulga D, Yamamoto K, Shimada K, Kario K, Yada T: Ghrelin counteracts salt-induced hypertension via promoting diuresis and renal nitric oxide production in dahl rats. Endocr J 2013;60:571-581.

15 Cheyuo C, Wu R, Zhou M, Jacob A, Coppa G, Wang P: Ghrelin suppresses inflammation and neuronal nitric oxide synthase in focal cerebral ischemia via the vagus nerve. Shock 2011;35:258-265.

16 Azizzadeh F, Mahmoodi J, Sadigh-Eteghad S, Farajdokht F, Mohaddes G: Ghrelin exerts analgesic effects through modulation of il-10 and tgf-beta levels in a rat model of inflammatory pain. Iran Biomed J 2016

17 Sibilia V, Lattuada N, Rapetti D, Pagani F, Vincenza D, Bulgarelli I, Locatelli V, Guidobono F, Netti C: Ghrelin inhibits inflammatory pain in rats: involvement of the opioid system. Neuropharmacology 2006;51:497505.

18 Zeng P, Li S, Zheng YH, Liu FY, Wang JL, Zhang DL, Wei J: Ghrelin receptor agonist, ghrp-2, produces antinociceptive effects at the supraspinal level via the opioid receptor in mice. Peptides 2014;55:103-109.

19 Sustkova-Fiserova M, Jerabek P, Havlickova T, Kacer P, Krsiak M: Ghrelin receptor antagonism of morphineinduced accumbens dopamine release and behavioral stimulation in rats. Psychopharmacology (Berl) 2014;231:2899-2908.

20 Kawahara Y, Kaneko F, Yamada M, Kishikawa Y, Kawahara H, Nishi A: Food reward-sensitive interaction of ghrelin and opioid receptor pathways in mesolimbic dopamine system. Neuropharmacology 2013;67:395402.

-21 Barreau F, de Lahitte JD, Ferrier L, Frexinos J, Bueno L, Fioramonti J: Neonatal maternal deprivation promotes nippostrongylus brasiliensis infection in adult rats. Brain Behav Immun 2006;20:254-260.

-22 Barreau F, Ferrier L, Fioramonti J, Bueno L: Neonatal maternal deprivation triggers long term alterations in colonic epithelial barrier and mucosal immunity in rats. Gut 2004;53:501-506.

23 Barreau F, Cartier C, Ferrier L, Fioramonti J, Bueno L: Nerve growth factor mediates alterations of colonic sensitivity and mucosal barrier induced by neonatal stress in rats. Gastroenterology 2004;127:524-534.

24 Gaman A, Kuo B: Neuromodulatory processes of the brain-gut axis. NEUROMODULATION 2008;11:249259.

25 Pustovit RV, Furness JB, Rivera LR: A ghrelin receptor agonist is an effective colokinetic in rats with dietinduced constipation. Neurogastroenterol Motil 2015;27:610-617.

26 Ejskjaer N, Dimcevski G, Wo J, Hellstrom PM, Gormsen LC, Sarosiek I, Softeland E, Nowak T, Pezzullo JC, Shaughnessy L, Kosutic G, McCallum R: Safety and efficacy of ghrelin agonist tzp-101 in relieving symptoms in patients with diabetic gastroparesis: a randomized, placebo-controlled study. Neurogastroenterol Motil 2010;22:1069-1281.

27 Xiao Y, Chen X, Zhang PA, Xu Q Zheng H, Xu GY: Trpv1-mediated presynaptic transmission in basolateral amygdala contributes to visceral hypersensitivity in adult rats with neonatal maternal deprivation. Sci Rep 2016;6:29026.

28 Szallasi A, Appendino G: Vanilloid receptor trpv1 antagonists as the next generation of painkillers. Are we putting the cart before the horse? J Med Chem 2004;47:2717-2723.

29 Yamamoto S, Ohsawa M, Ono H: Contribution of trpv1 receptor-expressing fibers to spinal ventral root after-discharges and mechanical hyperalgesia in a spared nerve injury (sni) rat model. J Pharmacol SCI 2013;121:9-16.

30 Schroeder JE, McCleskey EW: Inhibition of ca2+ currents by a mu-opioid in a defined subset of rat sensory neurons. J Neurosci 1993;13:867-873.

-31 Shaqura M, Khalefa BI, Shakibaei M, Zollner C, Al-Khrasani M, Furst S, Schafer M, Mousa SA: New insights into mechanisms of opioid inhibitory effects on capsaicin-induced trpv1 activity during painful diabetic neuropathy. Neuropharmacology 2014;85:142-150.

-32 Endres-Becker J, Heppenstall PA, Mousa SA, Labuz D, Oksche A, Schafer M, Stein C, Zollner C: Mu-opioid receptor activation modulates transient receptor potential vanilloid 1 (trpv1) currents in sensory neurons in a model of inflammatory pain. Mol Pharmacol 2007;71:12-18.

-33 Bao Y, Gao Y, Yang L, Kong X, Yu J, Hou W, Hua B: The mechanism of mu-opioid receptor (mor)-trpv1 crosstalk in trpv1 activation involves morphine anti-nociception, tolerance and dependence. Channels (Austin) 2015;9:235-243.

-34 Skibicka KP, Shirazi RH, Hansson C, Dickson SL: Ghrelin interacts with neuropeptide y y1 and opioid receptors to increase food reward. Endocrinology 2012;153:1194-1205. 